\title{
Use of psychoactive substances among teens and young people in schools in Benin: from experimentation to dependence
}

\author{
A. Odile Kougblenou ${ }^{1}$, Charles Sossa ${ }^{4}$, Ferdinand M. Adounkpe ${ }^{2}$, A. Assad. Bio Sya ${ }^{2}$, \\ C. Arnaud Agbanlinsou ${ }^{3}$, Eric Ayédjo Akpi ${ }^{1 *}$, Pierre Codjo Meliho ${ }^{1}$, Codjo Adolphe Kpatchavi ${ }^{1}$, \\ Dismand Houinato ${ }^{5}$, Anatole Laleye ${ }^{3}$
}

\begin{abstract}
${ }^{1}$ Laboratory of Sociology and Applied Medical Anthropology (LAMA), ${ }^{2}$ National Laboratory of Narcotics and Toxicology (LNST), ${ }^{3}$ Laboratory of Histology, Reproductive Biology, Cytogenetics and Medical Genetics (LHBRCGM), ${ }^{4}$ Regional Institute of Public Health (IRSP), ${ }^{5}$ Laboratory of Epidemiology of Chronic and Neurological Diseases (LEMACEN), Faculty of Health Sciences, University of Abomey-Calavi (UAC), Abomey-Calavi, Benin
\end{abstract}

Received: 07 November 2021

Revised: 27 December 2021

Accepted: 05 January 2022

\section{*Correspondence:}

Eric Ayédjo Akpi,

E-mail: ericakpi@gmail.com

Copyright: (C) the author(s), publisher and licensee Medip Academy. This is an open-access article distributed under the terms of the Creative Commons Attribution Non-Commercial License, which permits unrestricted non-commercial use, distribution, and reproduction in any medium, provided the original work is properly cited.

\section{ABSTRACT}

Background: The use of psychoactive substances among adolescents and young people in schools in Benin is growing despite its consequences on their health. This article analysed this practice, identified the types of use and their determinants along the consumption trajectory.

Methods: It was mixed, transversal study and involved 617 students from high schools and colleges in Cotonou and Parakou in 2020. Sampling was in two-degree clusters. 65 students were drawn by reasoned choice and snowball for qualitative interviews. Data processing was done with SPSS software and content analysis.

Results: The results show that there was a diversity of substances available, accessible and used by targets in the last three months prior to the survey. Three types of use were identified: experimental use, determined by curiosity $(48.14 \%)$, the quest for generational identity $(25.45 \%)$ and sociability $(34.20 \%)$; misuse, influenced by the quest for physical and sexual performance $(17.83 \%)$, intellectual performance $(28.85 \%)$ and peer pressure $(22.04 \%)$ and dependent use, determined by the precocity of experimentation $(69.04 \%)$, family type $(33.60 \%)$ and the relaxation of societal values.

Conclusions: Adolescents living in abusive and dependent uses are particularly vulnerable in terms of health and social. This requires a preventive approach based on education in societal values, the fight against the availability of these substances and the early management of cases of dependence.

Keywords: Adolescents, Dependence, Experimentation, Psychoactive substances

\section{INTRODUCTION}

Described in the literature as part of "deviant" behaviour, the use of psychoactive substances (SPA) has been the subject of several scientific reflections for more than 20 years, particularly in the medical and social sciences. ${ }^{1,2}$ It is perceived as a "new normal", a specificity linked to the juvenile condition and the construction of identity.,4
Particularly among adolescents, the use of SPAs is part of the field of experimentation and risk-taking. In this period of their biographical trajectory, adolescents have to build themselves as socialized individuals. They seek to discover themselves, test themselves, define their preferences, identify with groups and opt for worlds of socialization. ${ }^{5}$ Most of them have experience of a psychoactive substance for the first time at an early age while some are already settled in regular use at that age. ${ }^{6}$ 
Whatever the form of use, the consequences are multiple and very often inevitable on health and society as mentioned by the World Health Organization (WHO). Indeed, 1.7 million adolescents worldwide lose their lives each year, mainly due to traffic accidents, suicides and homicides, often associated with the use of psychoactive substances. ${ }^{7}$

In Africa in general and Benin in particular, the knowledge available to date sheds light on the phenomenon in a fragmentary way and it is difficult to provide a synthetic vision. There are, of course, the texts and laws voted on this subject in recent decades. Examples include Benin's ratification of the Framework Convention on Tobacco Control, the conventions on the organization, development and intensification of the fight against drugs and an anti-drug policy (POLUDRO).$^{8}$ In 2016, a study conducted by Kpatchavi and Adounkpè in 13 private high schools and colleges in Cotonou showed that the use of psychoactive substances among adolescents and young people in schools is increasing despite the public health risks and social problems it poses. ${ }^{9}$ However, the absence of an operational national data collection system does not allow an estimate of the extent of this problem among adolescents. ${ }^{10}$ This article analysed this deviant practice and identified the different types of use and their determinants, from the first experiment to the dependence on these substances by adolescents.

\section{METHODS}

This transversal research was based on two approaches: quantitative and qualitative. The field survey took place from March to April 2020, (forty-two days) in 20 high schools and colleges in the cities of Cotonou and Parakou, Benin. It focused on 617 adolescents and young people aged 10 to 24 from the $4^{\text {th }}$ to the final year. The latter were selected by the two-stage cluster sounding technique. Thus, from the sampling frame (list of public and private institutions in Benin), we drew at the first degree 10 establishments randomly at the rate of five (05) public and five (05) private in each of the cities. At the second degree, a class was drawn by chance by class level from the $4^{\text {th }}$ in terminale. In each of the clusters (the classes), we randomly took $1 / 5$ of the students.

With regard to the qualitative aspect of the research, 65 actors, including 40 adolescents and young people, five school leaders, three nurses and one officer responsible for the suppression of illicit trafficking in psychoactive substances, were selected from this sample by reasoned choice and snowball for in-depth individual and group interviews.

The data collection techniques used were the questionnaire and the individual and group interview. The quantitative data obtained was entered into the Kobocollect software and processed using the SPSS software, version 30. Qualitative data were processed by the content analysis method.

In addition, ethical provisions related to research involving human beings have been taken into account. The ISBA Research Ethics Committee (ISBA-CER) reviewed the research protocol and gave favorable approval under number 125 of February 11, 2020. This guaranteed respect for confidentiality and the protection of privacy as well as respect for the accuracy of the interlocutors' remarks.

\section{RESULTS}

\section{Socio-demographic and cultural characteristics of respondents}

In total, $67.1 \%$ of respondents attended public and private schools in Cotonou and $32.9 \%$ attended public and private schools in Parakou. Of these, $60.62 \%$ were male and $39.38 \%$ female. The most represented age was between 15 and 19 years $(71.8 \%)$. The $3^{\text {rd }}(28.69 \%)$ and terminale $(21.88 \%)$ levels were the most represented. The majority, $40.36 \%$ were Fon and $74.07 \%$ were Christian. A minority were orphans $(16.21 \%)$ and $48.3 \%$ lived in a two-parent family (Table 1).

\section{Ethnography of survey sites}

Public schools were located in the liveliest working-class areas of Cotonou and Parakou. They were mostly located near public and entertainment spaces, namely: beaches and stadiums, refreshment bars and game rooms where teenagers went to stock up and consume these products.

In private colleges, the school grounds were in itself an environment for the sale of these products. In addition to the cannabis that was sold in internists' dormitories, these SPAs were concealed in the form of sweets or cakes and marketed by teenagers and schoolchildren themselves.

Networks for the marketing of illegal substances whose SPAs had been set up around these public and private establishments. They were functional, complex and concealed. Their members were installed in kiosks sometimes called "chez dadjè", game rooms, unfinished buildings transformed into ghettos, bars and refreshment bars and in the streets.

The different spaces described above were categorized into two: the "school space: which included the school grounds (classroom, toilets, canteen, sports field) and the "extracurricular space" which included the immediate environment of the schools (kiosks, games rooms, unfinished buildings transformed into ghettos, bars and refreshment bars and in the streets). In this research, the extracurricular space, a privileged place for experimentation and continuation of consumption of SPAs represented $77.86 \%$ while the school space represented only $22.04 \%$. 
Table 1: Socio-demographic and cultural characteristics of respondents.

\begin{tabular}{|c|c|c|}
\hline & $\mathbf{n}$ & $\%$ \\
\hline \multicolumn{3}{|l|}{ Town } \\
\hline Cotonou & 414 & 67.1 \\
\hline Parakou & 203 & 32.9 \\
\hline \multicolumn{3}{|l|}{ Sex } \\
\hline Masculine & 374 & 60.38 \\
\hline Feminine & 243 & 39.38 \\
\hline \multicolumn{3}{|l|}{ Age group (in years) } \\
\hline $10-14$ & 86 & 13.94 \\
\hline $15-19$ & 443 & 71.8 \\
\hline $20-24$ & 88 & 14.26 \\
\hline \multicolumn{3}{|l|}{ Grade level } \\
\hline $4^{\text {th }}$ & 91 & 14.75 \\
\hline $3^{\text {rd }}$ & 177 & 28.69 \\
\hline $\mathrm{At}^{2: 00}$ & 135 & 21.88 \\
\hline $1^{\text {st }}$ era & 93 & 15.07 \\
\hline Terminal & 121 & 19.61 \\
\hline \multicolumn{3}{|l|}{ Family life } \\
\hline Biparentale & 298 & 48.3 \\
\hline Polygamous family & 54 & 8.75 \\
\hline Blended family & 45 & 7.29 \\
\hline Parent & 177 & 28.69 \\
\hline Other & 43 & 6.97 \\
\hline \multicolumn{3}{|l|}{ Ethnic group } \\
\hline Adja and related & 56 & 9.08 \\
\hline Bariba and related & 49 & 7.94 \\
\hline Betamaribe and related & 5 & 0.81 \\
\hline Dendi and related & 32 & 5.19 \\
\hline Phone & 249 & 40.36 \\
\hline Goun & 61 & 9.89 \\
\hline Fulani and related & 4 & 0.65 \\
\hline Yoa and lokpa and related & 8 & 1.3 \\
\hline Yoruba and related & 94 & 15.24 \\
\hline Other & 59 & 9.56 \\
\hline \multicolumn{3}{|l|}{ Religion } \\
\hline Christian & 457 & 74.07 \\
\hline Muslim & 149 & 24.15 \\
\hline Endogenous religion & 11 & 1.78 \\
\hline \multicolumn{3}{|l|}{ Orphan } \\
\hline Not & 517 & 83.79 \\
\hline Yes & 100 & 16.21 \\
\hline Other & 36 & 5.83 \\
\hline
\end{tabular}

\section{Different substances used in establishments}

Different categories of substances used by adolescents and young people three months before the survey were identified (Table 2). Among the most cited were alcohol (78.28\%), amphetamine-type stimulants (62.07\%) and tobacco $(45.06 \%)$.

The alcohol consumed by the targets came from drinks such as beers (Beninese, vody, despérados, etc.), wine, sodabi, rums or whiskey in sachets commonly known as Tiger, Azota, Passion, Tombo, Sewa. As for tobacco, the respondents stated that they smoked cigarettes (ORIS cigarettes $\left.{ }^{\circledR}\right)$, shisha. In addition to these substances, adolescents in private institutions reported using hard drugs such as ecstasy, morphine, cocaine-based cocktails or syrup at least once.

Table 2: Prevalence of experimentation with PPS.

\begin{tabular}{|lll|}
\hline SPA groups over the life course & N & $\%$ \\
\hline Alcohol & 483 & 78.28 \\
\hline Tobacco & 278 & 45.06 \\
\hline Drug & 57 & 9.24 \\
\hline Amphetamine-type stimulants & 383 & 62.07 \\
\hline Solvents & 30 & 4.86 \\
\hline Psychotropic drugs & 226 & 36.63 \\
\hline Hallucinogens & 19 & 3.08 \\
\hline
\end{tabular}

\section{Types of use and determinants}

Three forms of use have been identified among the targets. These are experimental use, misuse and dependent use. The determinants of each of these uses have been identified and described below.

\section{Experimental use}

Experimental use was fostered by the curiosity of teenagers, the quest for sociability and the quest for generational identity.

\section{Curiosity}

It appeared that almost half of the teenagers, or $48.14 \%$, had experimented with SPAs out of curiosity. Recreational breaks, weekends, holiday times, birthdays or excursions were opportunities for SPA experimentation with peers. The substances most cited for a first experiment were alcohol, cigarettes and shisha.

"I knew shisha in $4^{\text {th }}$ grade with a girl during a cultural day here (...) at LM and it was my $1^{\text {st }}$ year in college. She had the electronic shisha and she made me shoot a little, good until the end of the cultural day", (student, $1^{\text {st }}$, private, Parakou, 16 years old).

\section{The quest for generational identity}

The existential need for the adolescent to build his identity by composing between who he is in family and who he is in the school space (in the presence of friends) was also cited as an element favouring the experimentation of SPAs by $25.45 \%$ of respondents. This quest was reflected in the words of the latter by the expressions "feel important", "attract attention", make the "buzz" to translate the fact of being one of the most prominent people in their social environment. 


\section{The quest for sociability}

The first experiment is usually done in a context of sociability. It is based on perceptions built on the effects of SPAs in adolescents and conveyed in the school space.

The comments collected also reveal the influence of the internet and new social media on the sharing of experience and the encouragement of experimentation. Cannabis and cigarettes, as well as substances obtained in combination, were tested through these networks of sociability according to $34.20 \%$ of respondents.

"I hang out with the 'big guys' in my neighborhood, they're the ones who take that and I saw. I used to take cigarettes but when I took it (cannabis) once, I gave up smoking" (student, second, public, Cotonou).

\section{Abuse}

Misuse in this work refers to the regular consumption of SPAs. This consumption was determined by the quest for physical, sexual and intellectual performance or peer pressure.

\section{The quest for physical and sexual performance}

According to quantitative data, $17.83 \%$ of respondents reported using substances such as coffee, tramadol ${ }^{\circledR}$, cigarettes or even combining several SPAs in order to maintain optimal physical performance to go about income-generating extracurricular activities.

Others $(24.64 \%)$ had added that they have achieved this type of use because they aim to keep a better physical shape in order to "let off steam" at parties with friends and to "make love".

"Good! (...) it's for boys; when we take this (tramadol $\left.{ }^{\circledR}\right)$, we have strength, (...) after the girl even respects you" (student in class of $2^{\text {nd }}$, public college, Cotonou).

\section{The quest for intellectual performance}

A proportion of $28.85 \%$ of respondents had said that they had misused PPS because of price stress and the obligation of a positive return at the end of each semester. For this determinant, stimulants (coffee and cocaine) had been mentioned. They were sometimes combined with psychotropic drugs (tramadol $^{\circledR}$, especially) and alcohol (sodabi).

They would allow to be resilient to fatigue during the periods of revision and examination according to the representation that adolescents have of these substances.

"Very much I have coffee with sodabi; it gives energy and it allows you to stay awake a lot to study" (student in $3^{\text {rd }}$ grade, public college, Cotonou).

\section{Peer or consumer network pressure}

The need to belong to a group of friends, having first led to experimental use, kept some adolescents in a consumption group according to the statements of $22.04 \%$ of the targets. It was noted in the same remarks that as much as individuals joined forces to consume a substance, the sources of supply were diversified. This ensured the continued availability of SPAs and encouraged their misuse. This type of use was made in particular in extracurricular spaces such as beaches, streets, bars and playrooms where teenagers met regularly.

"It's that even if you don't have money, friends will share for them with you. Their presence forces you to always take your life is in danger because the decision to give up is like a threat to the group. They will be your enemies and (laughs) they will slap you and hey ma'am, even kill you" (student in $4^{\text {th }}$ grade, public college, Parakou).

As reported by these remarks, the teenagers perceived the cessation of consumption as a danger to their own lives because the group risked apprehending their decision as an act of betrayal of the bond that united them.

\section{Dependent use}

Dependent use is a form of consumption not controlled by the adolescent. Those who were confronted with this type of use were perpetually in search of new sensations and experienced several spa associations. Three factors favoured this use. These are:

\section{The precocity of experimentation}

In our sample, the majority of respondents $(69.04 \%)$ had experimented with PPS in the 11-16 age group, i.e. $77.37 \%$ for boys and $63.64 \%$ for girls (Table 3 ).

Table 3: Age at first experimentation of PPS.

\begin{tabular}{|c|c|c|c|c|c|c|}
\hline & \multicolumn{6}{|c|}{ Age of discovery (years) } \\
\hline & $(5-10)$ & $\%$ & $(11-16)$ & $\%$ & $(17-22)$ & $\%$ \\
\hline \multicolumn{7}{|l|}{ Sex } \\
\hline Masculine & 60 & 6.04 & 238 & 77.37 & 76 & 20.32 \\
\hline Feminine & 30 & 12.35 & 188 & 63.64 & 25 & 10.29 \\
\hline Total & 90 & 14.59 & 426 & 69.04 & 101 & 16.37 \\
\hline
\end{tabular}


Early experimentation with APS could be the cause of a rapid and uncontrollable shift in the problematic use of SPAs in adolescents. The data presented in this table indicated that this precocity is sensitive to the variable "sex" of consumers. It would be likely to increase the risk for the adolescent to develop an uncontrolled rhythm of use that would lead to dependence.

"It was when I was little (...) I was in $4^{\text {th }}$ grade (...), I tried to quit smoking for two months but I got sick 6 times... uh I had relapses of palu, if I do not have a hot body, I have stomach aches, if it is not stomach aches, it is that I do not eat and I become very thin (...) So I resumed" (student in class of $1^{\text {st }}$, public college, Parakou).

These remarks showed the gradual evolution of the consumption of SPAs by adolescents who experimented with the substance early in the family space.

\section{Family type: absence of a father figure}

Adolescents $(33.60 \%)$ in whom this type of use had been observed live in single-parent or blended families. During the qualitative interviews, $70 \%$ of them said they lived with their mothers or other relatives. The latter had mentioned the absence of a father figure (due to divorce, death or reason for work) as the cause of dependent use. Still others, for reasons of geographical inaccessibility to their establishment, come close to it to live either at the boarding school, or in rental or with a close relative (cousin, acquaintance of the parents) during the school year.

"I live with my mother and my little brother, dad is in Ivory Coast... when, between friends, the others talk about their dads, it annoys me and I withdraw a little... and if I am confused I take the shisha so that I can forget (...)" (student in class of $3^{\text {rd }}$,private college, Cotonou).

These teens mentioned the fact that they had low selfesteem due to lack of paternal affection and were continually confronted with the stresses generated by family conflicts at home. This state of affairs would lead the adolescent to fall back on a consumer group or on his peer consumers whom he considers to be his models.

"My dad passed away when I was born... I am the youngest of mom, I have a brother and a sister who are already working... I have a big brother who is my confidant, (...) it's thanks to him I'm with the guys and we share the beuh (...) when he forbids me to do something, I respect that. I tell him everything, it is he alone who advises me" (student in class of $1^{\text {st }}$, public college, Parakou).

\section{Relaxation of societal values}

In the logic of filling the void left by male parents, some mothers became less demanding even if it meant their parental responsibility. For this, they opted for a role that consisted of pampering the adolescent more than punishing him in case of misconduct harmful to his health and society. This would manifest itself in the complicit silence of the parents or their lack of reaction to the words of the school managers.

\section{DISCUSSION}

The results of this research have confirmed that alcohol, tobacco and amphetamines are the substances that adolescents experiment with. These same substances have been identified by Milhet in France; Nelson, et al in the United States; by Lopes et al, in Brazil; then Tarpomanova and Stefanova in Bulgaria with teenagers but in different proportions., ${ }^{2,7,11}$ Three types of use of these SPS have been identified in adolescents.

The determinants of experimental use were curiosity. This is in line with the factor identified by Tarpomanova and Stefanova's comparative descriptive study of adolescents in two high schools in Bulgaria. ${ }^{12}$ But the difference in proportions $(48.14 \%$ in Cotonou and Parakou against $65.3 \%$ in Kavarna and $55 \%$ in Dobrich) could be due to the size of the samples (198 against 617 adolescents in our work). The quest for generational identity also appears as a cause of experimentation among adolescents. This is in line with Le Breton's assertion that "the signs of identity in adolescents" points out that substance use can be a form of response to this existential need in adolescents. ${ }^{13}$ In addition, whether the discovery of SPAs takes place in the school or extracurricular area, it takes place in contexts of sociability and exchanges. The need to belong to a group, to be recognized by peers and to exist in the eyes of friends also weighs on the experimentation and highlights the socializing dimension of this practice among the respondents. ${ }^{14}$

In addition, the quest for physical (17.83\%), sexual $(24.64 \%)$ and intellectual $(28.85 \%)$ performance promotes the misuse of SPAs among adolescents. This was reported by Kpatchavi and Adounkpè in their study of 477 teenagers from private high schools and colleges in Cotonou. ${ }^{9}$ Without specifying proportions as in the context of this research, these authors explain that the misuse by the adolescent is part of the following logics: "increase the performance of the body by adapting it to the constraints of life in the school environment and the pace of work (12 hours at school); strengthen cognitive potential to cope with assessments and exams; overcome stress and anxiety (pressure from teachers and parents)". 9 The results indicate that $22.04 \%$ of the targets were set in abusive use because of peer pressure.

Similarly, Hadland et al showed on a sample of 860 teenagers in England that those who had switched from experimental to monthly use or more often were more likely to have close relatives or drug-addicted peers. ${ }^{15}$ This pressure was strong in schools: in middle school or high school. ${ }^{16}$ 
Dependent use is facilitated by the precocity of experimentation. In our sample, $69.04 \%$ of adolescents experienced SPAs in the 11-16 age group. Previous studies have already established that adolescents who engage in an experimental consumption trajectory at an early age are at high risk of being dependent on it. ${ }^{17}$ The results also highlighted the fact that the type of family in which the adolescent lives leads to this type of use. Very few studies have been able to establish this link. The relaxation of societal values was also identified by Kpatchavi and Adounkpè among adolescents in private high schools and colleges in Cotonou. ${ }^{9}$

However, it is important to mention the limitations of the study. The survey adopted the questionnaire interview, which is not without bias. There may be biases relating to the accuracy of the information provided. Also, the investigation took place in a context of repression of sellers of drugs on the parallel market and drug users which may have led to superficiality in the answers to the questions.

\section{CONCLUSION}

This article set out to analyse the use of psychoactive substances among adolescents. It brought empirical evidence to light three types of use, each determined by three factors: experimental use (1) is determined by the curiosity of adolescents (a), the quest for generational identity (b) and sociability (c). Misuse (2) is influenced by the quest for physical and sexual performance (a), intellectual performance (b) and peer pressure (c). Dependent use (3) is determined by the precocity of experimentation (a), the type of family (b) and the relaxation of societal values (c).

Adolescents and young people living in abusive and dependent use are particularly vulnerable in terms of health and social. This requires a preventive approach that must focus on education in societal values, the fight against the availability of these substances in the informal sector and early management of cases of dependence observed among adolescents.

\section{ACKNOWLEDGEMENTS}

This article is the result of a research project that has been approved and financially supported under the third competitive research fund programme (PFCR III) of the University of Abomey-Calavi (UAC).

Funding: This study was funded by Competitive Research Fund (PFCR III) of the University of Abomey-Calavi (UAC) Conflict of interest: None declared

Ethical approval: The ISBA Research Ethics Committee (ISBA-CER) reviewed the research protocol and gave favourable approval under number 125 of February 11, 2020

\section{REFERENCES}

1. Tricot N. Becker HS, Outsiders. Studies in the sociology of deviance. Revue française de sociologie. 1965;6(1):100-1.

2. Milhet M. Usages détournés de médicaments psychotropes par les adolescents et jeunes adultes. Literature review, Note 201508, Saint-Denis, OFDT, Available at: https://www.ofdt.fr/BDD/publications/docs/eisxmm vc.pdf.

3. Gaillard JP. Enfants et adolescents en mutation: Instructions for parents, educators, teachers and therapists (French) Paperback. Ed. Art De La Psychothérapie; 2009:208.

4. Petiau A, Pourtau L, Galand C. From the discovery of psychoactive substances in a techno party environment to controlled use. Drugs Health Soc. 2009;8(1):165-99.

5. Milhet M, Langlois E. Facing the trials of juvenile life: the misuse of psychotropic drugs in youth. Dev Soc. 2017;41(4):511-40.

6. Spilka S, Le Nézet O, Ngantcha M, Beck F. Drugs at 17: analysis of the ESCAPAD survey 2014. Trends. 2015;100 (8).

7. Lopes GM, Nóbrega BA, Del Prette G, Scivoletto S. Use of psychoactive substances by adolescents: current panorama. Br J Psychiatr. 2013;35:S51-61.

8. World Organization of Health Regional Office for Africa, 2001, Mobilizing the community and social actors in favor of the national drug policy about fifty executives and specialists examined this subject in Porto-Novo. Available from: http://www.geocities.ws/omsbenin/19mobidro.html, Accessed on 13 December 2021.

9. Kpatchavi A, Adounkpe F. Use of drugs and addictive substances a propension among adolescents in Benin: a survey in the high schools of Cotonou. Ann Univ de Lomé Sér Lett. 2016;XXXVI-2:239-49.

10. Aguemon B, Gansou M, Damien GB, Padonou G, Djossou E, Dahissiho L, Consumption of psychoactive substances and associated factors in schools in the commune of Bohicon (Benin). J de la Recherche Scientifique de l'Université de Lomé. 2017;19(3).

11. Nelson SE, Van Ryzin MJ, Dishion TJ. Alcohol, marijuana, and tobacco use trajectories from age 12 to 24 years: demographic correlates and young adult substance use problems. Develop Psychopathol. 2015;27(1):253-77.

12. Tarpomanova $\mathrm{T}$, Stefanova $\mathrm{R}$, Determinants of psychoactive substance abuse among students from $7^{\text {th }}$ to $9^{\text {th }}$ grade in Kavarna and Dobrich- a comparative study. Forum Médical de Varna. 2018;7(3).

13. Le Breton D, the adolescent scene: signs of identity. Adolescence. 2005;3:587-602.

14. Imaine S. Preventing substance use in adolescence. Proposal and testing of the method by self-reaction 
and of the tool. Ageven Psychotropes. 2015;21(2):131-56.

15. Hadland ES, Copelas HS, Harris KS. Trajectories of substance use frequency among adolescents seen in primary care: implications for screening. J Pediatre. 2017;184:178-85.

16. Cheryl A, Piazza M, Mekos D, Valente TP. Schools, and adolescent cigarette smoking. J Adoloesc Health. 2001;29(1):22-30.

17. Martínez-Loredoa V, Fernández-Hermidaa JR, de La Torre-Luqueb A, Fernández-Artamendic S.
Polydrug use trajectories and differences in impulsivity among adolescents. Int J Clin Health Psychol. 2018;18:235-44.

Cite this article as: Kougblenou AO, Sossa C, Adounkpe FM, Sya AAB, Agbanlinsou CA, Akpi EA, et al. Use of psychoactive substances among adolescents and young people in schools in Benin: from experimentation to dependence. Int $\mathbf{J}$ Community Med Public Health 2022;9:619-25. 